\title{
An Ovarian Reserve Assessment Model Based on Anti-Müllerian Hormone Levels, Follicle-Stimulating Hormone Levels, and Age: Retrospective Cohort Study
}

Huiyu Xu ${ }^{1,2,3,4^{*}}, \mathrm{PhD} ; \mathrm{Li} \mathrm{Shi}^{1,2,3,4^{*}}, \mathrm{MA}$; Guoshuang Feng ${ }^{5 *}$, PhD; Zhen Xiao ${ }^{6}$, BA; Lixue Chen ${ }^{1,2,3,4}$, BA; Rong Li ${ }^{1,2,3,4}$, MD, PhD; Jie Qiao ${ }^{1,2,3,4}, \mathrm{MD}, \mathrm{PhD}$

\footnotetext{
${ }^{1}$ Center for Reproductive Medicine, Department of Obstetrics and Gynecology, Peking University Third Hospital, Beijing, China

${ }^{2}$ Key Laboratory of Assisted Reproduction, Ministry of Education, Beijing, China

${ }^{3}$ National Clinical Research Center for Obstetrics and Gynecology, Beijing, China

${ }^{4}$ Beijing Key Laboratory of Reproductive Endocrinology and Assisted Reproductive Technology, Beijing, China

${ }^{5}$ Big Data and Engineering Research Center, Beijing Children's Hospital, Capital Medical University, Beijing, China

${ }^{6}$ Zhejiang Provincial People's Hospital, Hangzhou, China

*these authors contributed equally
}

\section{Corresponding Author:}

Rong Li, MD, PhD

Center for Reproductive Medicine

Department of Obstetrics and Gynecology

Peking University Third Hospital

49 Huayuan North, Haidian District

Beijing,

China

Phone: 861082266836

Email: roseli001@sina.com

\section{Abstract}

Background: Previously, we reported a model for assessing ovarian reserves using 4 predictors: anti-Müllerian hormone (AMH) level, antral follicle count (AFC), follicle-stimulating hormone (FSH) level, and female age. This model is referred as the AAFA (anti-Müllerian hormone level-antral follicle count-follicle-stimulating hormone level-age) model.

Objective: This study aims to explore the possibility of establishing a model for predicting ovarian reserves using only 3 factors: AMH level, FSH level, and age. The proposed model is referred to as the AFA (anti-Müllerian hormone level-follicle-stimulating hormone level-age) model.

Methods: Oocytes from ovarian cycles stimulated by gonadotropin-releasing hormone antagonist were collected retrospectively at our reproductive center. Poor ovarian response $(<5$ oocytes retrieved) was defined as an outcome variable. The AFA model was built using a multivariable logistic regression analysis on data from 2017; data from 2018 were used to validate the performance of AFA model. Measurements of the area under the curve (AUC), sensitivity, specificity, positive predictive value, and negative predicative value were used to evaluate the performance of the model. To rank the ovarian reserves of the whole population, we ranked the subgroups according to the predicted probability of poor ovarian response and further divided the 60 subgroups into 4 clusters, A-D, according to cut-off values consistent with the AAFA model.

Results: The AUCs of the AFA and AAFA models were similar for the same validation set, with values of 0.853 (95\% CI 0.841-0.865) and 0.850 (95\% CI 0.838-0.862), respectively. We further ranked the ovarian reserves according to their predicted probability of poor ovarian response, which was calculated using our AFA model. The actual incidences of poor ovarian response in groups from A-D in the AFA model were 0.037 (95\% CI 0.029-0.046), 0.128 (95\% CI 0.099-0.165), 0.294 (95\% CI 0.250-0.341), and 0.624 (95\% CI 0.577-0.669), respectively. The order of ovarian reserve from adequate to poor followed the order from A to D. The clinical pregnancy rate, live-birth rate, and specific differences in groups A-D were similar when predicted using the AFA and AAFA models.

Conclusions: This AFA model for assessing the true ovarian reserve was more convenient, cost-effective, and objective than our original AAFA model. 
(J Med Internet Res 2020;22(9):e19096) doi: 10.2196/19096

\section{KEYWORDS}

ovarian reserve; poor ovarian response; $\mathrm{AMH}$; $\mathrm{AFC}$; FSH; logistic regression

\section{Introduction}

The antral follicle count (AFC) is the number of follicles $<8$ $\mathrm{mm}$ in diameter in early gonadotropin-dependent follicular growth. It has been widely accepted that the pool of primordial follicles in the ovary-the ovarian reserve-is related to the number of growing antral follicles. Thus, in theory, the AFC reflects the remaining ovarian follicle pool [1-3]. However, obtaining an accurate AFC demands a time- and resource-consuming ultrasound examination by a skilled transvaginal sonography specialist. The lack of standardization in AFC measurements [4], AFC changes through the menstrual cycle, contraceptive use [5], and the sensitivity and resolution of transvaginal sonography equipment are all confounding factors making the reliable assessment of AFC difficult.

We have previously published a model for estimating ovarian reserves, using 4 predictors: anti-Müllerian hormone (AMH) level, the AFC, follicle-stimulating hormone (FSH) level, and age. This model was named as the AAFA (anti-Müllerian hormone level-antral follicle count-follicle-stimulating hormone level-age) model [6]. With the development of accurate AMH assays $[7,8]$, the level of this hormone might replace the use of $\mathrm{AFC}$ in the measurement of ovarian reserve, avoiding the complexity, cost, and interobserver variation in the AFC $[9,10]$. Here, we aimed to explore the possibility of establishing a model for assessing a true ovarian reserve using the 3 predictors: AMH levels, FSH levels, and age. This model is referred to as the AFA (anti-Müllerian hormone level-follicle-stimulating hormone level-age) model. If the performance of the AFA model without using the AFC is only slightly worse or even similar to the 4-predictor AAFA model, it might be of better clinical significance, especially in physical examination centers or third-party clinical laboratories, which cannot perform AFC measurements by transvaginal sonography.

\section{Methods}

\section{Subjects}

This was a retrospective observational cohort study using the same dataset as in our previous study [6]. Briefly, data from 2017 to 2018 were selected according to the inclusion and exclusion criteria. In total, we selected 1523 oocytes from ovarian cycles stimulated by a gonadotropin-releasing hormone (GnRH) antagonist 2017 and 3273 oocytes, from 2018. The first and second stimulation cycles were included as described by $\mathrm{Xu}$ et al [6], and there were no strict restrictions on the women's age or body mass index. Diseases potentially related to defects in follicular development were excluded, including ovarian cysts, previous ovarian surgery, polycystic ovarian syndrome, previous metabolic or endocrinological diseases, previous tuberculosis, chromosomal abnormalities, and women with pregnancies within the previous 3 months. The need for informed consent by the patients was waived, and institutional review board approval was not needed for the de-identified data in this retrospective analysis, as per the Declaration of Helsinki [11].

\section{Sampling and Endocrine Assays}

Venous blood samples were drawn, and the sample tubes were immediately inverted 5 times to facilitate thorough blood clotting. Serum was collected by centrifugation and used for endocrine assessment. The circulating FSH level was measured on menstrual cycle day 2, and the circulating AMH level was measured on any day of the menstrual cycle. Serum FSH measurements were performed using a Siemens Immulite 2000 immunoassay system (Siemens Healthcare Diagnostics). The quality controls used for the FSH assay were Lypocheck Immunoassay Plus Control, Trilevel, catalog number 370, lot number 40340 (Bio-Rad Laboratories). Serum AMH concentrations were measured by an ultrasensitive 2-site enzyme-linked immunosorbent assay (Ansh Laboratories), using quality controls supplied within the kits. The coefficients of variation for each assay were indicated previously [6].

\section{Statistical Analysis}

In this study, poor ovarian response with $<5$ oocytes retrieved was defined as an outcome variable. The predictor variables were age and basal serum FSH and AMH concentrations. A multivariable logistic regression analysis was performed to construct a predictive model for poor ovarian response to stimulation using 2017 data; the data from 2018 were used to validate the performance of that model. Measurements of the area under the curve (AUC), sensitivity, specificity, positive predictive value (PPV), and negative predicative value (NPV) were used to evaluate the predictive models. The main effect of each predicting variable measures the variation over the distribution of $x_{\mathrm{j}}$ in the mean poor ovarian response. Venn diagrams were used to compare the differences between the AAFA and AFA models.

To rank the ovarian reserve of the whole population, we ranked subgroups according to the predicted probability of poor ovarian response and further divided the 60 subgroups into 4 groups A-D, according to cut-off values consistent with our established AAFA model [6]. Analyses were conducted using SAS JMP Pro (version 14.2; SAS Institute), and $P<.05$ was considered statistically significant.

\section{Results}

We previously established an AAFA model, using the 4 predictors of AMH, AFC, FSH, and age [6]. We used this to classify the study population into 4 subgroups: A, B, C and D.

However, the lack of standardization in AFC measurements [4] makes the reliable assessment of AFC very difficult. Moreover, the AFCs were well correlated with AMH, FSH, or age [12,13], implying collinearity. Therefore, we sought to explore the possibility of establishing a model for assessment of the true 
ovarian reserve using only 3 predictors-AMH, FSH, and age (ie, the AFA model) — instead of the previous 4-predictor AAFA model [6].

\section{Multivariable Logistic Regression to Build a Predictive Model for Poor Ovarian Response Using the 2017 Data}

Basic characteristics of the treatment cycles are shown in Table 1.

Table 1. Basic characteristics of treatment cycles.

\begin{tabular}{lll}
\hline Characteristics & $2017(\mathrm{n}=1523)$ & $2018(\mathrm{n}=3273)$ \\
\hline Age (years), Mean (SD) & $33.4(5.3)$ & $32.7(4.8)$ \\
Basal FSH $^{\mathrm{a}}(\mathrm{IU} / \mathrm{L})$, Mean (SD) & $7.5(3.3)$ & $7.2(3.1)$ \\
$\mathrm{AMH}^{\mathrm{b}}(\mathrm{ng} / \mathrm{mL})$, Median (IQR) & $2.2(1.1-4.0)$ & $2.7(1.2-4.8)$ \\
\hline
\end{tabular}

${ }^{\mathrm{a}} \mathrm{FSH}$ : follicle-stimulating hormone.

b AMH: anti-Müllerian hormone.

Table 2. Comparison of grouping criteria of the AFA and AAFA models.

\begin{tabular}{|c|c|c|c|c|c|c|c|}
\hline \multirow[t]{2}{*}{ Grouping criteria } & \multicolumn{5}{|c|}{$\mathrm{AFA}^{\mathrm{a}}$ model groups } & \multicolumn{2}{|c|}{$\mathrm{AAFA}^{\mathrm{b}}$ model groups } \\
\hline & 0 & 1 & 2 & 3 & 4 & 0 & 1 \\
\hline $\mathrm{AMH}^{\mathrm{c}}(\mathrm{ng} / \mathrm{mL})$ & $<0.5$ & 0.5 to $<1$ & 1 to $<1.5$ & 1.5 to $<2$ & $\geq 2$ & $\geq 1.2$ & $<1.2$ \\
\hline $\begin{array}{l}\text { Basal FSH }^{\mathrm{d}} \\
(\mathrm{IU} / \mathrm{L})\end{array}$ & $<6.5$ & 6.5 to $<8.5$ & 8.5 to $<10.5$ & $\geq 10.5$ & N/A & $\leq 8$ & $>8$ \\
\hline Age (years) & $\leq 30$ & $>30$ to 40 & $>40$ & N/A & N/A & $\leq 35$ & $>35$ \\
\hline $\mathrm{AFC}^{\mathrm{e}}$ & N/A & N/A & N/A & N/A & N/A & $\geq 8$ & $<8$ \\
\hline
\end{tabular}

aAA: Anti-Müllerian hormone level-Follicle-stimulating hormone level-Age.

bAAFA: Anti-Müllerian hormone level-Antral follicle count-Follicle-stimulating hormone level-Age.

${ }^{\mathrm{c}} \mathrm{AMH}$ : anti-Müllerian hormone.

${ }^{\mathrm{d}} \mathrm{FSH}$ : follicle-stimulating hormone.

e AFC: antral follicle count.

The transformed categorical variables were then analyzed using multivariable logistic regression. The main effects that each independent variable exerted in this model were AMH $(85.2 \%)$, followed by FSH (6.8\%), and age (2.8\%). Thus, we have named

this model as AFA based on the order of the main effects of each predictor. The odds ratios of each predictor are indicated in Table 3. 
Table 3. The odd ratios of each predictor in the AFA model.

\begin{tabular}{|c|c|c|}
\hline Predictors & OR $(95 \% \mathrm{CI})$ & $P$ value \\
\hline Intercept & $1.753(1.177-2.611)$ & $<.001$ \\
\hline Categorical age ( 1 vs 0 ) & $2.239(1.344-3.731)$ & .006 \\
\hline Categorical age (2 vs 0 ) & $1.863(1.270-2.734)$ & .002 \\
\hline Categorical FSH ${ }^{\mathrm{a}}$ (1 vs 0 ) & $2.300(1.438-3.681)$ & .002 \\
\hline Categorical FSH (2 vs 0) & $3.594(2.333-5.538)$ & .001 \\
\hline Categorical FSH (3 vs 0) & $24.641(14.997-40.488)$ & $<.001$ \\
\hline Categorical $\mathrm{AMH}^{\mathrm{b}}$ (0 vs 4$)$ & $11.431(7.281-17.945)$ & $<.001$ \\
\hline Categorical AMH (1 vs 4) & $5.010(3.167-7.928)$ & $<.001$ \\
\hline Categorical AMH (2 vs 4) & $2.211(1.259-3.882)$ & $<.001$ \\
\hline Categorical AMH (3 vs 4) & $1.753(1.177-2.611)$ & .006 \\
\hline
\end{tabular}

${ }^{\mathrm{a}} \mathrm{FSH}$ : follicle-stimulating hormone.

${ }^{\mathrm{b}} \mathrm{AMH}$ : anti-Müllerian hormone.

\section{Comparing the Performances of the AFA and AAFA Models}

To further evaluate the performance of this AFA model, we calculated the AUC, sensitivity, specificity, PPV, and NPV in the training set (2017 data) and the validation set (2018 data) as indicated in Table 4.

A calibration plot was drawn to evaluate the calibration performance of the AFA model in the training set and validation set (Multimedia Appendix 1). The performance of the AAFA model in the validation set (2018 data) is indicated in Table 4. A comparison shows that the AUCs of the AFA and AAFA models for the same validation set are similar at 0.853 (95\% CI $0.841-0.865$ ) and 0.850 (95\% CI 0.838-0.862), respectively. The specificity, sensitivity, PPV, and NPV are also indicated in Table 4. The AUC between AFA model and AAFA model was tested with DeLong test. The difference of the 2 models in AUC level is 0.009 (95\% CI -0.004 to 0.022$)$, indicating no significant difference.

Table 4. The performance of AFA model.

\begin{tabular}{|c|c|c|c|}
\hline \multirow[t]{2}{*}{ Performance indicators } & \multicolumn{2}{|l|}{$\mathrm{AFA}^{\mathrm{a}}$ model } & \multirow{2}{*}{$\begin{array}{l}\text { AAFA }^{\mathrm{b}} \text { model } \\
\text { Validation set, OR }(95 \% \mathrm{CI})\end{array}$} \\
\hline & Training set, OR (95\% CI) & Validation set, OR (95\% CI) & \\
\hline $\mathrm{AUC}^{\mathrm{c}}$ & $0.860(0.843-0.877)$ & $0.853(0.841-0.865)$ & $0.850(0.838-0.862)$ \\
\hline Sensitivity & $0.511(0.456-0.566)$ & $0.489(0.445-0.533)$ & $0.519(0.475-0.563)$ \\
\hline Specificity & $0.940(0.925-0.952)$ & $0.949(0.940-0.957)$ & $0.930(0.920-0.939)$ \\
\hline $\mathrm{PPV}^{\mathrm{d}}$ & $0.688(0.626-0.744)$ & $0.633(0.585-0.680)$ & $0.570(0.525-0.615)$ \\
\hline $\mathrm{NPV}^{\mathrm{e}}$ & $0.881(0.862-0.897)$ & $0.911(0.901-0.922)$ & $0.915(0.904-0.925)$ \\
\hline
\end{tabular}

aAA: Anti-Müllerian hormone level-Follicle-stimulating hormone level-Age.

bAAFA: Anti-Müllerian hormone level-Antral follicle count-Follicle-stimulating hormone level-Age.

${ }^{\mathrm{c}} \mathrm{AUC}$ : area under the curve.

${ }^{\mathrm{d}} \mathrm{PPV}$ : positive predictive value.

${ }^{\mathrm{e}} \mathrm{NPV}$ : negative predictive value.

The numbers of overlapping and nonoverlapping cases in the predicted positive (poor ovarian response) and negative estimated by the 2 models are shown in Figure 1.
There were 328 positive (poor responders) and 2732 negative (nonpoor responders) cases overlapping in the 2 models. The 2 models had $93.5 \%$ (3060/3273) overlapping positive and negative cases in the 2018 validation set. 
Figure 1. Comparison of the performances of the AFA and AAFA models in the 2018 validation data.
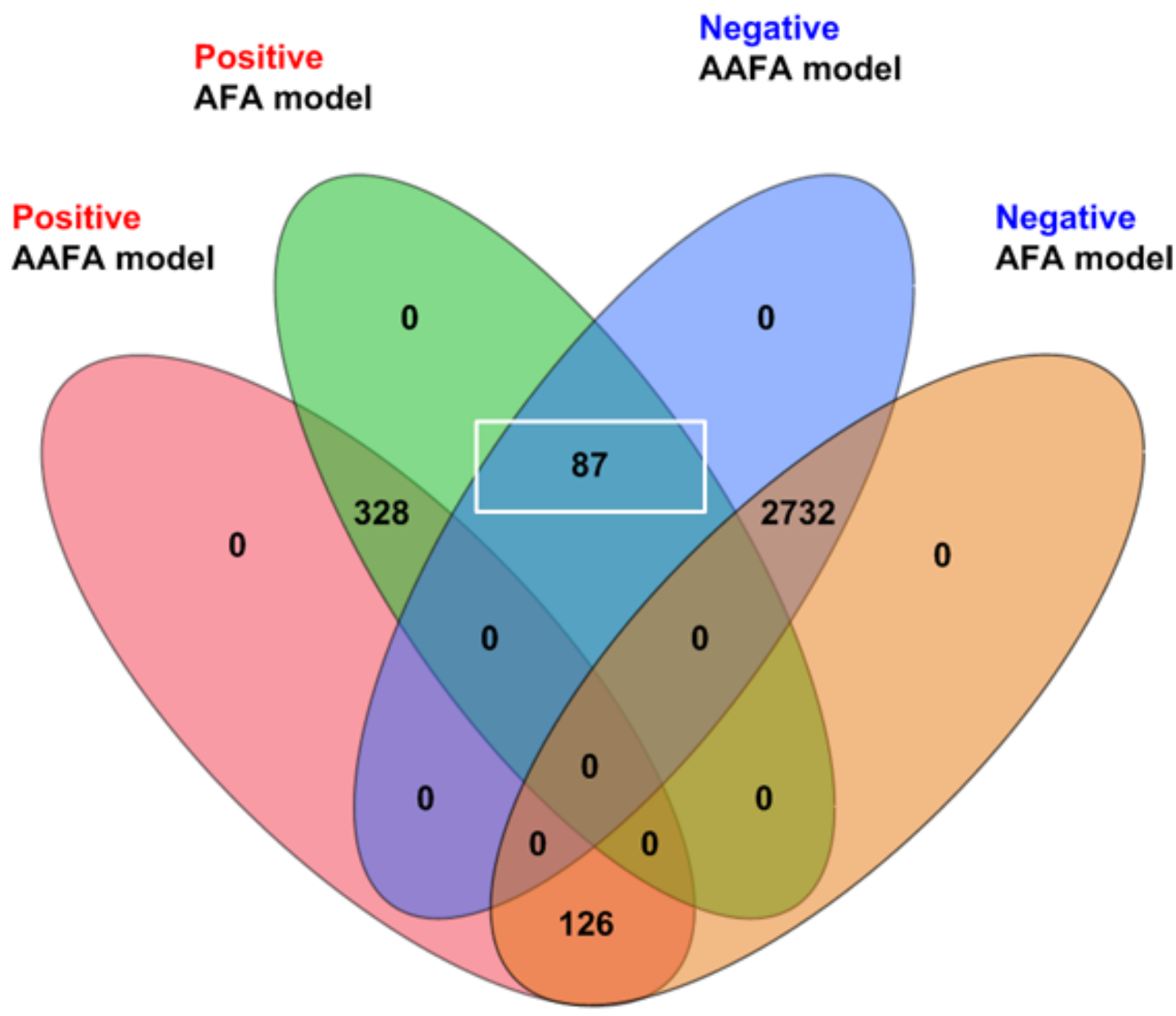

\section{Ranking the Ovarian Reserve Based on the Predicted Probability of a Poor Ovarian Response}

We previously ranked the ovarian reserve of the whole population according to the predicted probability of a poor ovarian response [6], given that the number of oocytes retrieved is closely related to the number of primordial follicles in the ovarian cortex [14-16]. In this study, we used the same method to rank the ovarian reserve according to the predicted probability of a poor ovarian response calculated using the AFA model. The 60 groups were further divided into 4 subgroups: A, B, C, and D (Multimedia Appendix 2).
The order of ovarian reserve from adequate to poor followed the order of predicted probability of a poor ovarian response from low to high. Women with a predicted probability of more than $50 \%$ were classified into the population with diminished ovarian reserve (namely, group D that includes subgroups 43-60), as shown in Multimedia Appendix 2. The actual incidences of poor ovarian response, clinical pregnancy rate per starting cycle, clinical pregnancy rate per embryo transfer cycle, live-birth rate per starting cycle, and live-birth rate per embryo transfer cycle (with 95\% CIs) are also indicated in Table 5. 
Table 5. The clinical pregnancy rate and live-birth rate in the 4 ovarian reserve groups.

\begin{tabular}{|c|c|c|c|c|c|}
\hline $\begin{array}{l}\text { Ovarian reserve } \\
\text { group and model }\end{array}$ & $\begin{array}{l}\text { Actual incidence of } \\
\text { poor ovarian response } \\
(95 \% \mathrm{CI})\end{array}$ & $\begin{array}{l}\mathrm{CP}^{\mathrm{a}} \text { per } \\
\text { starting Cycles } \\
(95 \% \mathrm{CI})\end{array}$ & $\begin{array}{l}\text { CP per } \mathrm{ET}^{\mathrm{b}} \text { cycles } \\
(95 \% \mathrm{CI})\end{array}$ & $\begin{array}{l}\mathrm{LB}^{\mathrm{c}} \text { per } \\
\text { starting Cycles } \\
(95 \% \mathrm{CI})\end{array}$ & $\begin{array}{l}\text { LB per ET cycles } \\
(95 \% \mathrm{CI})\end{array}$ \\
\hline \multicolumn{6}{|l|}{ A } \\
\hline $\mathrm{AFA}^{\mathrm{d}}$ & $\begin{array}{l}0.037 \\
(0.029-0.046)\end{array}$ & $\begin{array}{l}0.217 \\
(0.199-0.235)\end{array}$ & $\begin{array}{l}0.454 \\
(0.424-0.486)\end{array}$ & $\begin{array}{l}0.176 \\
(0.160-0.193)\end{array}$ & $\begin{array}{l}0.368 \\
(0.339-0.399)\end{array}$ \\
\hline $\mathrm{AAFA}^{\mathrm{e}}$ & $\begin{array}{l}0.038 \\
(0.030-0.046)\end{array}$ & $\begin{array}{l}0.212 \\
(0.195-0.229)\end{array}$ & $\begin{array}{l}0.439 \\
(0.409-0.469)\end{array}$ & $\begin{array}{l}0.174 \\
(0.158-0.190)\end{array}$ & $\begin{array}{l}0.360 \\
(0.331-0.388)\end{array}$ \\
\hline \multicolumn{6}{|l|}{ B } \\
\hline AFA & $\begin{array}{l}0.128 \\
(0.099-0.165)\end{array}$ & $\begin{array}{l}0.165 \\
(0.123-0.205)\end{array}$ & $\begin{array}{l}0.298 \\
(0.242-0.361)\end{array}$ & $\begin{array}{l}0.138 \\
(0.108-0.175)\end{array}$ & $\begin{array}{l}0.249 \\
(0.197-0.309)\end{array}$ \\
\hline AAFA & $\begin{array}{l}0.139 \\
(0.101-0.177)\end{array}$ & $\begin{array}{l}0.210 \\
(0.166-0.254)\end{array}$ & $\begin{array}{l}0.370 \\
(0.300-0.439)\end{array}$ & $\begin{array}{l}0.167 \\
(0.126-0.207)\end{array}$ & $\begin{array}{l}0.294 \\
(0.228-0.359)\end{array}$ \\
\hline \multicolumn{6}{|l|}{ C } \\
\hline AFA & $\begin{array}{l}0.294 \\
(0.250-0.341)\end{array}$ & $\begin{array}{l}0.157 \\
(0.124-0.197)\end{array}$ & $\begin{array}{l}0.277 \\
(0.221-0.340)\end{array}$ & $\begin{array}{l}0.142 \\
(0.110-0.180)\end{array}$ & $\begin{array}{l}0.249 \\
(0.196-0.310)\end{array}$ \\
\hline AAFA & $\begin{array}{l}0.362 \\
(0.308-0.415)\end{array}$ & $\begin{array}{l}0.140 \\
(0.101-0.179)\end{array}$ & $\begin{array}{l}0.402 \\
(0.309-0.495)\end{array}$ & $\begin{array}{l}0.124 \\
(0.087-0.161)\end{array}$ & $\begin{array}{l}0.355 \\
(0.265-0.446)\end{array}$ \\
\hline \multicolumn{6}{|l|}{ D } \\
\hline AFA & $\begin{array}{l}0.624 \\
(0.577-0.669)\end{array}$ & $\begin{array}{l}0.135 \\
(0.105-0.171)\end{array}$ & $\begin{array}{l}0.289 \\
(0.229-0.356)\end{array}$ & $\begin{array}{l}0.080 \\
(0.057-0.110)\end{array}$ & $\begin{array}{l}0.170 \\
(0.124-0.229)\end{array}$ \\
\hline AAFA & $\begin{array}{l}0.571 \\
(0.525-0.616)\end{array}$ & $\begin{array}{l}0.126 \\
(0.095-0.156)\end{array}$ & $\begin{array}{l}0.268 \\
(0.208-0.327)\end{array}$ & $\begin{array}{l}0.077 \\
(0.053-0.102)\end{array}$ & $\begin{array}{l}0.164 \\
(0.114-0.213)\end{array}$ \\
\hline
\end{tabular}

${ }^{\mathrm{a}} \mathrm{CP}$ : clinical pregnancy.

${ }^{\mathrm{b}} \mathrm{ET}$ : embryo transfer.

${ }^{\mathrm{c}} \mathrm{LB}$ : live birth.

${ }^{\mathrm{d}} \mathrm{AFA}$ : Anti-Müllerian hormone level-Follicle-stimulating hormone level-Age.

eAAFA: Anti-Müllerian hormone level-Antral follicle count-Follicle-stimulating hormone level-Age.

Comparing Specific Differences Between the AFA and AAFA Models in Groups A-D

Figure 2 displays the specific differences between the AFA and AAFA models in classifying the whole population into groups A-D.

The horizontal axis includes the 3273 cases in the 2018 validation data. The 2 models did not show a 3-level difference; that is, there was no case classified as A (good ovarian reserve) by the AAFA model but as D (diminished ovarian reserve) by the AFA model. In addition, most cases were classified into the same groups by both models. However, there were differences for some cases. We focus on 3 groups having 2-level differences defined by the AFA or AAFA models, as shown by the red, green, and purple arrows in Figure 2. The same colors are used to indicate those 3 groups in Figure 3. 
Figure 2. Specific differences between the AAFA and AFA models in A-D groups.

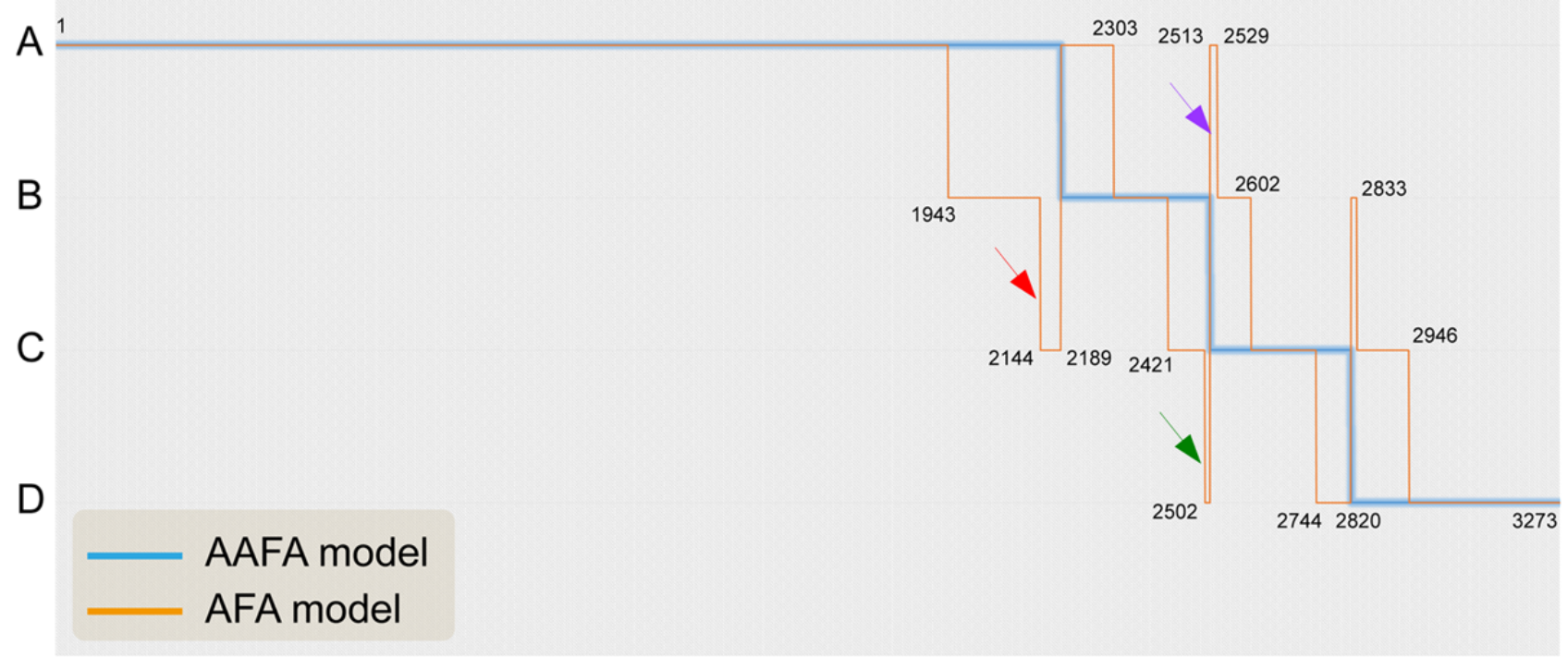

Figure 3. Specific differences between the AAFA and AFA models in A-D groups (tabular form).

\begin{tabular}{|c|c|c|c|}
\hline $\begin{array}{l}\text { AAFA } \\
\text { classification }\end{array}$ & $\begin{array}{l}\text { AFA } \\
\text { classification }\end{array}$ & $\begin{array}{l}\text { Number of } \\
\text { samples }\end{array}$ & Specific groups (1-60 groups) \\
\hline \multirow[t]{3}{*}{ A } & A & 1942 & $1-11$ \\
\hline & B & 201 & $12-15,17-19,21-26,28-29$ \\
\hline & $\mathrm{C}$ & 45 & $30,34,35,41$ \\
\hline \multirow[t]{4}{*}{$\mathrm{B}$} & A & 114 & $2,5-10$ \\
\hline & B & 118 & $12-15,17-24,26-29$ \\
\hline & $\mathrm{C}$ & 81 & $30,32-37,39,41-42$ \\
\hline & $\mathrm{D}$ & 11 & $43,45,46,53$ \\
\hline \multirow[t]{4}{*}{$\mathrm{C}$} & $\mathrm{A}$ & 16 & 10 \\
\hline & B & 73 & $14,16-17,21-22,24,26-27,29$ \\
\hline & $\mathrm{C}$ & 142 & $30-34,36-42$ \\
\hline & $\mathrm{D}$ & 76 & $43-50,52-54,56-57,59$ \\
\hline \multirow[t]{3}{*}{$\mathrm{D}$} & B & 13 & $21,26,28$ \\
\hline & $\mathrm{C}$ & 113 & $30,32-35,38-42$ \\
\hline & $\mathrm{D}$ & 328 & $43-45,47-60$ \\
\hline
\end{tabular}

The raw data and the corresponding predicted probability of a poor ovarian response in the 2 models are listed in Multimedia Appendix 3. The actual incidences of poor ovarian response in the 3 subgroups were 4/45 (red), 5/11 (green), and 1/16 (brown). These results suggest that for the red subgroup, the AAFA classification might be closer to the actual incidence of poor ovarian response (4/45). Thus, these cases should have been placed in group A, rather than in the group C. However, for the purple subgroup with a poor ovarian response incidence of 1/16, the group A classified by AFA model might be more suitable. For the green subgroup with a poor ovarian response incidence of $5 / 11$, not group B by the AAFA model or group D by the AFA model, but group $\mathrm{C}$ is more appropriate with its predicted probability of $30 \%$ to $50 \%$. For groups having 1-level differences, specific cohorts are shown in Figure 2, Figure 3, and Multimedia Appendix 3. 


\section{Discussion}

We previously established our AAFA model to assess ovarian reserve based on AMH, AFC, FSH, and age [6]. However, standardization of the AFC has long been difficult for fertility clinics worldwide. In this study, using the same 2018 validation data without the AFC predictor, the AFA model showed similar performance as that of the AAFA model, with an AUC of 0.853 (95\% CI 0.841-0.865) vs 0.850 (95\% CI 0.838-0.862) for the AAFA model. Since it does not require the AFC, the applicability and cost-effectiveness of the AFA model is better than the AAFA model. Thus, a large number of first- and second-tier hospitals, physical examination centers, or third-party clinical laboratories, which cannot conduct AFC tests, can now assess ovarian reserve using our AFA model.

There were no large (3-level) differences, in that no subject was classified into the A group by the AAFA model and the D group by the AFA model (Figure 2 and Multimedia Appendix 3). There were at most 2 levels of difference, as shown in Figure 2 , indicated in red, green, and purple. After referring to the actual rate of poor ovarian response in these groups, we came to the conclusion that the 2 models have their own benefits and can complement each other in assessing ovarian reserve. Integration of these 2 models might give infertility clinics more individualized recommendations before starting controlled ovarian stimulation.

The global infertility rate is increasing, affecting about 1 in 7 couples [17]. A large proportion of women worldwide choose to delay having their first child for pursuit of opportunities to improve their education and workforce participation. It has long been acknowledged that fertility (the ability to establish a clinical pregnancy) decreases with increasing female age. Thus, the prevalence of infertility is increasing worldwide due to the postponement of childbearing. However, many women of reproductive age are not aware of the existing large heterogeneity in ovarian reserve for the same age [18]. In response to the increasing of infertility rate, to achieve a successful pregnancy, an increasing number of couples seek for assisted reproductive treatment. However, not all couples will benefit from it, as the beneficial effect of assisted reproductive treatment is limited in women with diminished ovarian reserve or in women with premenopause [19,20]. If women with potential diminished ovarian reserve could evaluate their ovarian reserve status earlier, it might be possible to avoid the subsequent infertility problem. Our new AFA model provides better means for assessing ovarian reserve, so that women of childbearing age, especially those who hesitate to start a family, might be able to evaluate their ovarian reserve in time.

The circulating AMH concentration is well-correlated with the $\mathrm{AFC}$, and it is considered to be the best predictor for an ovarian response [3,14,21,22]. However, it should be noted that AMH concentrations and AFC are not necessarily linked. The term "ovarian reserve" refers to the number of primordial follicles remaining in the ovarian cortex. AMH is secreted by immature granulosa cells in the gonadotropin-independent phase of follicular development, while the AFC reflects the later gonadotropin-dependent phase. For example, in patients with hypogonadotropic hypogonadism, AFC is undetectable because of the extremely low level of FSH, but such young patients can have a sufficient ovarian reserve, manifested by normal AMH levels and good pregnancy outcomes when undergoing assisted reproductive technology. In addition, some patients exhibit a diminished ovarian reserve and low AMH concentrations but have a satisfactory AFC. AMH gene knockout mice might help us to understand the underlying mechanisms in such patients. In these mice, diminished ovarian reserve induced by the absence of AMH leads to accelerated follicular activation and an increase in the AFC in 4-month-old AMH-null mice (young adult) [23]. Therefore, it is possible that the AMH concentration is a more accurate measure of the actual ovarian reserve than the AFC. Furthermore, the main effect of AMH level was $62.0 \%$ in our AAFA model, and $85.2 \%$ in the AFA model, meaning that this hormone is the best predictor of ovarian reserve among the existing indicators.

The relationship between AMH concentration and pregnancy outcomes has been investigated extensively [14,24-27]. Fertility is defined as the natural capability to establish a clinical pregnancy [28]. The most accepted predictor for fertility is the ovarian reserve. Within a certain range, the number of primordial follicles does not correlate well with fertility [6], but when the number falls below a certain threshold, as in the case of diminished ovarian reserve defined by our AAFA [6] or AFA models (Table 5), female fertility declines significantly. This might explain the relatively weak relationship between fertility and ovarian reserve. There is a large variation in the number of granulosa cells needed to maintain at least 1 healthy oocyte; however, if there are too few granulosa cells to support at least 1 healthy oocyte, pregnancy is not possible.

There were some limitations to our study. First, it had a retrospective and nonrandomized design. However, as one of the largest reproductive centers in China, there is no strict limit on our selection of patients, thus helping avoid selection bias among our study population. Therefore, our AFA model is relevant to daily clinical practice. Second, our AFA model divides the population into 60 subgroups $(3 \times 4 \times 5)$ rather than the 16 subgroups in the AAFA model. Thus, the sample sizes in our groups were relatively small, such as the 20th group (Multimedia Appendix 2) with only 1 case. We aim to include more samples in the future to verify and improve our formula used in the AFA model. Our last concern is that the positive rate predicted by the validation set (2018 data) is lower than the training set (2017 data), which may be induced by the lower rate of actual poor responders in 2018 data (315/1523 in 2017 data vs 499/3273 in 2018 data). Although the predicted positive rate of the validation set is low, considering the similarity of the AUC of the training set and the validation set, and the main purpose of our research, which is to classify the whole population into more groups according to the predicted probability of poor ovarian response, we believe that the AFA model is satisfactory and comparable to AAFA model. For subsequent related software, we will also integrate the AFA model, the AAFA model, and the actual rate of poor ovarian response in each subgroup together to further optimize the algorithm of this ovarian reserve assessment-related software. 


\section{Acknowledgments}

We thank James Cummins, PhD, from Liwen Bianji, Edanz Group China, for editing the English text of a draft of this manuscript. This study was supported by the National Key Research and Development Program of China (Grant No. 2016YFC1000201, 2018YFC1002104, 2018YFC1002106, 2016YFC1000302); National Natural Science Foundation of China (Grant No. 81300373, 81771650); the Capital Health Research and Development of Special Project (Grant No. 2018-1-4091); Program for the Innovative Research Team of Yunnan, China (Grant No. 2017HC009); and Major National R \& D Projects of China (Grant No. 2017ZX09304012-012).

\section{Conflicts of Interest}

None declared.

\section{Multimedia Appendix 1}

A calibration plot of the AFA model in the training set and validation set.

[PNG File, 36 KB-Multimedia Appendix 1]

\section{Multimedia Appendix 2}

Ranking the ovarian reserve into 4 subgroups of A-D based on predicted probability of poor ovarian response in validation data. [DOCX File , 25 KB-Multimedia Appendix 2]

\section{Multimedia Appendix 3}

Raw data and corresponding predicted groups and subgroups classified by the AFA or AAFA models. [XLSX File (Microsoft Excel File), 443 KB-Multimedia Appendix 3]

\section{References}

1. de Carvalho BR, Rosa e Silva ACJDS, Rosa e Silva JC, dos Reis RM, Ferriani RA, Silva de Sá MF. Ovarian reserve evaluation: state of the art. J Assist Reprod Genet 2008 Jul;25(7):311-322 [FREE Full text] [doi: 10.1007/s10815-008-9241-2] [Medline: $\underline{18679790]}$

2. Broer SL, Mol BWJ, Hendriks D, Broekmans FJ. The role of antimullerian hormone in prediction of outcome after IVF: comparison with the antral follicle count. Fertil Steril 2009 Mar;91(3):705-714. [doi: 10.1016/j.fertnstert.2007.12.013] [Medline: 18321493 ]

3. Broer SL, Dólleman M, Opmeer BC, Fauser BC, Mol BW, Broekmans FJM. AMH and AFC as predictors of excessive response in controlled ovarian hyperstimulation: a meta-analysis. Hum Reprod Update 2011;17(1):46-54. [doi: 10.1093/humupd/dmq034] [Medline: 20667894]

4. Broekmans FJ, de Ziegler D, Howles CM, Gougeon A, Trew G, Olivennes F. The antral follicle count: practical recommendations for better standardization. Fertil Steril 2010 Aug;94(3):1044-1051. [doi: 10.1016/j.fertnstert.2009.04.040] [Medline: 19589513]

5. Somunkiran A, Yavuz T, Yucel O, Ozdemir I. Anti-Müllerian hormone levels during hormonal contraception in women with polycystic ovary syndrome. Eur J Obstet Gynecol Reprod Biol 2007 Oct;134(2):196-201. [doi: 10.1016/j.ejogrb.2007.01.012] [Medline: 17335955]

6. Xu H, Feng G, Wang H, Han Y, Yang R, Song Y, et al. A novel mathematical model of true ovarian reserve assessment based on predicted probability of poor ovarian response: a retrospective cohort study. J Assist Reprod Genet 2020 Apr;37(4):963-972. [doi: 10.1007/s10815-020-01700-1] [Medline: 32318905]

7. Li H, Wong B, Ip W, Yeung W, Ho P, Ng E. Comparative evaluation of three new commercial immunoassays for anti-Müllerian hormone measurement. Hum Reprod 2016 Dec;31(12):2796-2802. [doi: 10.1093/humrep/dew248] [Medline: 27702835]

8. Ferguson JM, Pépin D, Duru C, Matejtschuk P, Donahoe PK, Burns CJ. Towards international standardization of immunoassays for Müllerian inhibiting substance/anti-Müllerian hormone. Reprod Biomed Online 2018 Nov;37(5):631-640 [FREE Full text] [doi: $\underline{10.1016 / j . r b m o .2018 .08 .012]}$ [Medline: 30241771$]$

9. Indran IR, Huang Z, Khin LW, Chan JK, Viardot-Foucault V, Yong EL. Simplified 4-item criteria for polycystic ovary syndrome: A bridge too far? Clin Endocrinol (Oxf) 2018 Aug;89(2):202-211. [doi: 10.1111/cen.13755] [Medline: 29851127]

10. Eilertsen TB, Vanky E, Carlsen SM. Anti-Mullerian hormone in the diagnosis of polycystic ovary syndrome: can morphologic description be replaced? Hum Reprod 2012 Aug;27(8):2494-2502. [doi: 10.1093/humrep/des213] [Medline: 22693172]

11. World Medical Association. World Medical Association Declaration of Helsinki: ethical principles for medical research involving human subjects. JAMA 2013 Nov 27;310(20):2191-2194. [doi: 10.1001/jama.2013.281053] [Medline: 24141714] 
12. Nyström A, Mörse H, Nordlöf H, Wiebe K, Artman M, Øra I, et al. Anti-müllerian hormone compared with other ovarian markers after childhood cancer treatment. Acta Oncol 2019 Feb;58(2):218-224. [doi: 10.1080/0284186X.2018.1529423] [Medline: $\underline{30558460}$ ]

13. Baker VL, Gracia C, Glassner MJ, Schnell VL, Doody K, Coddington CC, et al. Multicenter evaluation of the Access AMH antimüllerian hormone assay for the prediction of antral follicle count and poor ovarian response to controlled ovarian stimulation. Fertil Steril 2018 Aug;110(3):506-513.e3. [doi: 10.1016/j.fertnstert.2018.03.031] [Medline: 29960708]

14. Xu H, Zeng L, Yang R, Feng Y, Li R, Qiao J. Retrospective cohort study: AMH is the best ovarian reserve markers in predicting ovarian response but has unfavorable value in predicting clinical pregnancy in $\mathrm{GnRH}$ antagonist protocol. Arch Gynecol Obstet 2017 Mar;295(3):763-770. [doi: 10.1007/s00404-016-4274-8] [Medline: 28012077]

15. Broer S, van Disseldorp J, Broeze K, Dolleman M, Opmeer BC, Bossuyt P, IMPORT study group. Added value of ovarian reserve testing on patient characteristics in the prediction of ovarian response and ongoing pregnancy: an individual patient data approach. Hum Reprod Update 2013;19(1):26-36. [doi: 10.1093/humupd/dms041] [Medline: 23188168]

16. Qiao J, Wang Z, Feng H, Miao YL, Wang Q, Yu Y, et al. The root of reduced fertility in aged women and possible therapentic options: current status and future perspects. Mol Aspects Med 2014 Aug;38:54-85. [doi: 10.1016/j.mam.2013.06.001] [Medline: 23796757]

17. Talmor A, Dunphy B. Female obesity and infertility. Best Pract Res Clin Obstet Gynaecol 2015 May;29(4):498-506. [doi: 10.1016/j.bpobgyn.2014.10.014] [Medline: 25619586]

18. Daan NM, Fauser BC. Menopause prediction and potential implications. Maturitas 2015 Nov;82(3):257-265. [doi: 10.1016/j.maturitas.2015.07.019] [Medline: 26278873]

19. Hoorens S, Gallo F, Cave J, Grant J. Can assisted reproductive technologies help to offset population ageing? An assessment of the demographic and economic impact of ART in Denmark and UK. Hum Reprod 2007 Sep;22(9):2471-2475. [doi: 10.1093/humrep/dem181] [Medline: 17586831$]$

20. Habbema JDF, Eijkemans MJ, Nargund G, Beets G, Leridon H, Te Velde ER. The effect of in vitro fertilization on birth rates in western countries. Hum Reprod 2009 Jun;24(6):1414-1419. [doi: 10.1093/humrep/dep004] [Medline: 19233869]

21. Buyuk E, Seifer DB, Younger J, Grazi RV, Lieman H. Random anti-Müllerian hormone (AMH) is a predictor of ovarian response in women with elevated baseline early follicular follicle-stimulating hormone levels. Fertil Steril 2011 Jun;95(7):2369-2372. [doi: 10.1016/j.fertnstert.2011.03.071] [Medline: 21497340]

22. Nardo LG, Gelbaya TA, Wilkinson H, Roberts SA, Yates A, Pemberton P, et al. Circulating basal anti-Müllerian hormone levels as predictor of ovarian response in women undergoing ovarian stimulation for in vitro fertilization. Fertil Steril 2009 Nov;92(5):1586-1593. [doi: 10.1016/j.fertnstert.2008.08.127] [Medline: 18930213]

23. Durlinger AL, Kramer P, Karels B, de Jong FH, Uilenbroek JT, Grootegoed JA, et al. Control of primordial follicle recruitment by anti-Müllerian hormone in the mouse ovary. Endocrinology 1999 Dec;140(12):5789-5796. [doi: 10.1210/endo.140.12.7204] [Medline: 10579345]

24. Merhi Z, Zapantis A, Berger DS, Jindal SK. Determining an anti-Mullerian hormone cutoff level to predict clinical pregnancy following in vitro fertilization in women with severely diminished ovarian reserve. J Assist Reprod Genet 2013 Oct;30(10):1361-1365 [FREE Full text] [doi: 10.1007/s10815-013-0077-z] [Medline: 23963620]

25. Lukaszuk K, Liss J, Kunicki M, Jakiel G, Wasniewski T, Woclawek-Potocka I, et al. Anti-Müllerian hormone (AMH) is a strong predictor of live birth in women undergoing assisted reproductive technology. Reprod Biol 2014 Sep;14(3):176-181. [doi: 10.1016/j.repbio.2014.03.004] [Medline: 25152514]

26. Tal R, Seifer DB, Wantman E, Baker V, Tal O. Antimüllerian hormone as a predictor of live birth following assisted reproduction: an analysis of 85,062 fresh and thawed cycles from the Society for Assisted Reproductive Technology Clinic Outcome Reporting System database for 2012-2013. Fertil Steril 2018 Feb;109(2):258-265. [doi: 10.1016/j.fertnstert.2017.10.021] [Medline: 29331235]

27. Styer AK, Gaskins AJ, Brady PC, Sluss PM, Chavarro JE, Hauser RB, et al. Dynamic antimüllerian hormone levels during controlled ovarian hyperstimulation predict in vitro fertilization response and pregnancy outcomes. Fertil Steril 2015 Nov;104(5):1153-61.e1. [doi: 10.1016/j.fertnstert.2015.07.1161] [Medline: 26315051]

28. Zegers-Hochschild F, Adamson GD, Dyer S, Racowsky C, de Mouzon J, Sokol R, et al. The International Glossary on Infertility and Fertility Care, 2017. Fertil Steril 2017 Sep;108(3):393-406 [FREE Full text] [doi: 10.1016/j.fertnstert.2017.06.005] [Medline: 28760517]

\section{Abbreviations}

AFA: Anti-Müllerian hormone level-Follicle-stimulating hormone level-Age

AFAA: Anti-Müllerian hormone level-Antral follicle count-Follicle-stimulating hormone level-Age

AFC: antral follicle count

AMH: anti-Müllerian hormone

AUC: area under the curve

FSH: follicle-stimulating hormone

GnRH: gonadotropin-releasing hormone 
NPV: negative predicative value

PPV: positive predictive value

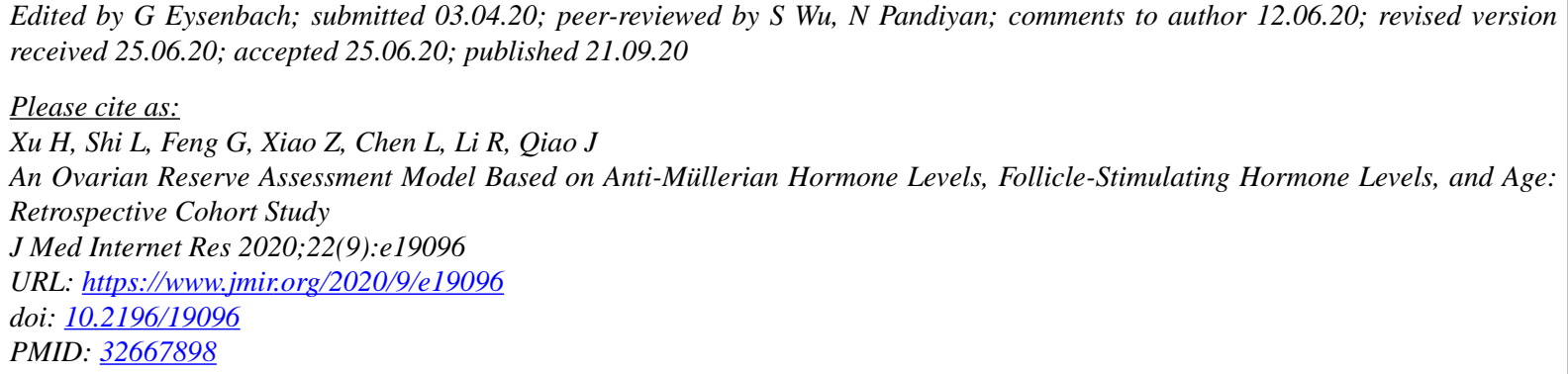

(CHuiyu Xu, Li Shi, Guoshuang Feng, Zhen Xiao, Lixue Chen, Rong Li, Jie Qiao. Originally published in the Journal of Medical Internet Research (http://www.jmir.org), 21.09.2020. This is an open-access article distributed under the terms of the Creative Commons Attribution License (https://creativecommons.org/licenses/by/4.0/), which permits unrestricted use, distribution, and reproduction in any medium, provided the original work, first published in the Journal of Medical Internet Research, is properly cited. The complete bibliographic information, a link to the original publication on http://www.jmir.org/, as well as this copyright and license information must be included. 